\title{
The Diffusion of IT in the Historical Context of Innovations from Developed Countries
}

\author{
Jeffrey James
}

Accepted: 27 December 2011/Published online: 13 January 2012

(C) The Author(s) 2012. This article is published with open access at Springerlink.com

\begin{abstract}
The well-known s-shaped diffusion of technology curve generally works well in developed countries. But how does it perform in the very different context of developing countries? Across a wide range of new technologies imported from the developed countries it works poorly. In most cases the penetration rate fails to reach $25 \%$ of the population. The reason for this as I see it has to do with the concentration of innovations in the rich countries and the devotion of R\&D to rich rather than poor country problems. I redrew the s-shaped curve to reflect these facts. At the other extreme, however, are technologies such as the mobile phone, which have reached a penetration rate in some developing countries that is higher than in certain developed countries. The underlying reason for this unusual experience is thought to be leapfrogging, the conditions for which are especially favourable in the case of mobile phones. Therefore there is a need to redraw the curve that explains the diffusion of most new technologies in developing countries.
\end{abstract}

Keywords Leapfrogging - Technological dualism - Mobile phones · s-Shaped curve

Conceptually, the paper revolves around the well-known S-shaped diffusion curve of technology diffusion proposed by Everett Rogers. This curve has received wide support as a theory of how technology works in developed countries. After an initial discussion of the theory I turn to a large data-base compiled by the World Bank which, going back in history and covering multiple technologies, shows that the s-shaped curve works poorly in developing countries. There, it seems, innovations get "stuck" in their diffusion trajectories well before the majority of the population has been reached. The reason for this finding is then examined. It turns out to involve the relationship between the generation of a technology and its subsequent diffusion. In particular the heavy biases in favour of technology generation in the developed countries mean that they do not usually take into account the problems and circumstances in the poor regions of the world. In recent years however a set of new information technologies has emerged and the data show that their

J. James $(\square)$

Development Economics, Tilburg University, Warandelaan 2, 5000 LE Tilburg, The Netherlands

e-mail: m.j.james@uvt.nl 
pattern of diffusion is closer to and even greater than the one found in the developed countries. I find the explanation to lie in leapfrogging and examine two such technologies from this point of view, namely digital switching and mobile phones. The circumstances required for successful leapfrogging are most favourable in the latter technology.

\section{The Rogers Diffusion Curve: Developed Versus Developing Countries}

Beginning with the assumption that the proportion of the population adopting an innovation is roughly normally distributed over time, the cumulative rate of adoption can be represented by the s-shaped curve in Fig. 1. This general shape, however, can take different forms. For example, low-cost innovations may exhibit a rapid take off while innovations with network effects may have faster late-stage growth.

Rogers divides the population of adopters into five groups, namely, innovators, early adopters, early majority, late majority and laggards. The size of each group is given respectively as $2.5,13.5,34,34,16$ (Rogers 1983). Some authors suggest that these categories can be classified by income level, running from early adopters (high) to laggards (low) but until recently no one has attempted a systematic review of the issue.

The exceptional case comprises a data-set compiled (from another source) by the World Bank (2008). In particular,

this data set traces the extent of diffusion of some 100 technologies in 157 countries during the period 1750-2003. For each technology, only countries for which published data exist are included .... The data analyzed here are further restricted to include only those country-technology pairs (a data set with one country and data for 7 technologies would have 7 country-technology pairs) where the intensity of use has reached at least 5 per cent of the average level of the 10 countries with the highest recorded level of diffusion. Under this restriction, there are 1,181 country-technology pairs, 699 of which correspond to developing countries (The World Bank 2008, p. 87).

One way of presenting the material thus identified is useful in comparing rates of diffusion in developed and developing countries over a number of different periods (see Table 1).

Fig. 1 The s-shaped curve

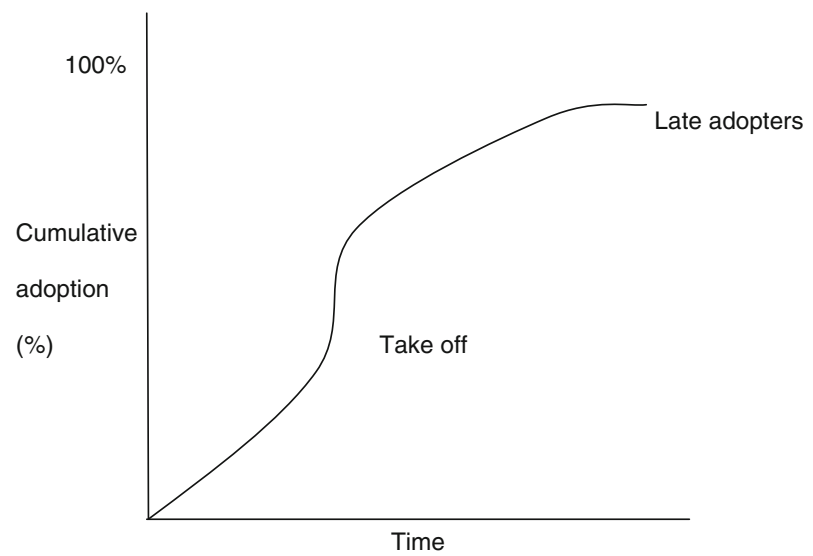


Table 1 Diffusion of innovations in rich and poor countries

\begin{tabular}{|c|c|c|c|c|c|c|c|c|c|c|c|c|}
\hline & \multicolumn{3}{|c|}{$1800 \mathrm{~s}$} & \multicolumn{3}{|c|}{$1900-1950$} & \multicolumn{3}{|c|}{$1950-1975$} & \multicolumn{3}{|c|}{$1975-2000$} \\
\hline & \multicolumn{3}{|c|}{ Threshold } & \multicolumn{3}{|c|}{ Threshold } & \multicolumn{3}{|c|}{ Threshold } & \multicolumn{3}{|c|}{ Threshold } \\
\hline & $5 \%$ & $25 \%$ & $50 \%$ & $5 \%$ & $25 \%$ & $50 \%$ & $5 \%$ & $25 \%$ & $50 \%$ & $5 \%$ & $25 \%$ & $50 \%$ \\
\hline High-income OECD & 150 & 114 & 75 & 174 & 93 & 55 & 96 & 87 & 75 & 28 & 26 & 23 \\
\hline Other high income & 25 & 16 & 7 & 28 & 23 & 14 & 14 & 10 & 8 & 7 & 6 & 6 \\
\hline Upper-middle & 90 & 30 & 6 & 112 & 53 & 16 & 61 & 24 & 4 & 29 & 19 & 6 \\
\hline Lower-middle & 109 & 8 & 2 & 130 & 38 & 12 & 33 & 0 & 0 & 33 & 5 & 0 \\
\hline Low-income & 17 & 0 & 0 & 76 & 15 & 6 & 4 & 0 & 0 & 5 & 0 & 0 \\
\hline \multicolumn{13}{|l|}{$\begin{array}{l}\text { Total number of } \\
\text { country-technology } \\
\text { pairs }\end{array}$} \\
\hline World & 391 & 168 & 90 & 480 & 222 & 102 & 208 & 121 & 87 & 105 & 56 & 35 \\
\hline Developing countries & 216 & 38 & 8 & 318 & 106 & 34 & 98 & 24 & 4 & 67 & 24 & 6 \\
\hline
\end{tabular}

Source: World Bank (2008)

The main insight from the table is that diffusion in developing countries only rarely reaches a rate of $25 \%$ and even more rarely of $50 \%$, with both rates well below what developed countries have achieved. 'For developing countries, the pace (and extent) of diffusion is significantly slower (lower) than in high-income countries, with only 24 (36 percent) developing countries having reached the 25 percent threshold and only 6 (9 percent) having reached the 50 percent threshold. This slower diffusion is true even for extremely old technologies, a result consistent with the idea that affordability and competency issues are binding constraints on the further diffusion of technologies in these countries' (World Bank 2008, p. 90). The corresponding figures for high-income OECD countries are that 26 out of 28 country-technologies have reached 25 and 23 have risen to at least $50 \%$ (see Table 1).

The conclusions from these and other data in the Bank report have been clearly stated by The Economist (2008) in the following terms:

In almost all industrialised countries, once a technology is adopted it goes on to achieve mass-market scale, reaching $25 \%$ of the market for that particular device. Usually it hits $50 \%$....

In emerging markets this is not necessarily so. The bank has 67 examples of a technology reaching $5 \%$ of the market in developing countries - but only six went on to capture half the national market. Where it did catch on, it usually spread as quickly as in the West. But the more striking finding is that the spread was so rare. Developing countries have been good at getting access to technology - and much less good at putting it to widespread use.

As a result, technology use in developing countries is highly concentrated.

Plainly, the curve drawn in Fig. 1 for the developed countries is not an accurate representation of what goes on in the developing world. In Fig. 2 I have tried to juxtapose the diffusion curves for both regions.

The main difference between the curves is that the one depicting developing countries tends to flatten out at a relatively low penetration rate. 


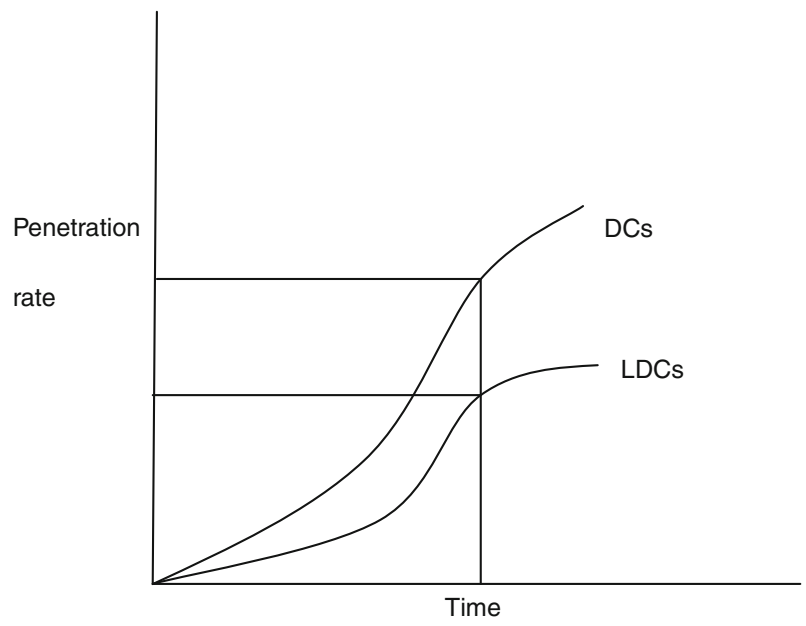

Fig. 2 Developed vs developing countries

Within developing countries it is very likely that diffusion will also be better represented over time by the lower curve shown in Fig. 2. This is not so much because there isn't a group of early adopters but more because rural areas are left virtually untouched by new technologies. India, for example, is one of the most technologically sophisticated developing countries with complex industries situated in and around the major cities. But advanced technologies have barely spread to the rural areas where the bulk of the less affluent members of the society is to be found. On a per capita basis, therefore, India has a relatively low level of technology diffusion. The accompanying 'skewed distribution of enterprise productivity implies potentially huge productivity and output increases are possible, if already existing within-country knowledge were to diffuse from top performers to the rest of the economy. Assuming that domestic competencies were available (or created) to efficiently use the technologies employed by enterprises at the national frontier, Indian GDP could be 4.8 times higher if those technologies were successfully applied by their less productive rivals' (World Bank 2008, p. 92). A similar story could be told for Brazil and certain other large developing countries.

The next part of the paper will try to show that both patterns of diffusion that have just been described between rich and poor countries and within the latter themselves - can be ascribed to the same source.

\section{An Explanation}

With the partial exception of India and China, the vast majority of global innovative activity (measured in R\&D or patents) takes place in the developed parts of the world. (especially Japan, the USA and Western Europe). According to the National Science Foundation in the United States, for example, 'Although many countries conduct R and D, much of global $\mathrm{R}$ and $\mathrm{D}$ performance continues to be concentrated in a few high-income countries and regions' (NSF 2010). This is both a cause and effect of being developed: $\mathrm{R}$ and $\mathrm{D}$ expenditures helped create high incomes, while richer countries could better afford such expenditure. 
The concentration of global research expenditure thus described would not necessarily constitute a bias in favour of rich countries and rich persons within countries as it is possible in principle that:

the direction of advance, the scientific and technological priorities and the methods of solving scientific and technological problems; were independent of where the work is carried on. This, however, is patently not the case, the [then] 98 per cent of research and development expenditures in the richer-countries are spent on solving the problems which concern the richer countries, according to their own priorities, and on solving these problems by the methods and approaches appropriate to the factor endowment of the richer countries. In both respects ... the interest of the poorer countries would be bound to point in completely new directions (Singer 1970, p. 62, emphasis added).

These directions would not however be confined, as Singer suggests, to factor endowments. For, as Stewart (1977) and others have pointed out, innovations are generated against the backdrop of a wide range of societal features. I am thinking here for example of labour skills, literacy, infrastructure and institutions. So even countries and regions with per capita incomes equal to the innovating country will tend to be lacking in these other ways. What will emerge in diffusion patterns across and within countries may be termed technological dualism. One part of the world (or a region within a country) has access to the innovations designed in and for the innovators while a much larger part is excluded from the benefits of research activity. The location of such activity in particular regions influences patterns of diffusion which in turn help determine the impact of new technologies. ${ }^{1}$ There are of course exceptions to this general pattern-as when, for example, a rich country institution specifically focuses on the poor in the developing world ${ }^{2}$ - but they represent only a small deviation from the observed tendency towards technological dualism.

The case of China, with a pronounced increase in $R \& D$ in recent years, promises a more substantial deviation. As yet however the characteristics of Chinese innovations-whether they are pro-rich or pro-poor-have not been systematically examined. But the increased capacity of this country to absorb foreign technology (even when it is complex), will certainly make its diffusion curve look more like the S-Shaped Rogers version discussed above. $^{3}$

\section{The Case of IT}

In general and in common with other innovations from the $\mathrm{R}$ and $\mathrm{D}$ intensive countries noted above, one may expect the innovations in IT to follow the systematic patterns of diffusion and adoption that have been described as technological dualism. For one thing, one might expect the new technologies to spread most extensively to regions that closely resemble the socio-economic features of innovating countries, including per capita income as a central variable. This means the more affluent among developing countries and more advanced (urban) areas of those parts of the world. Again though, it has to be stressed that

\footnotetext{
1 A widespread diffusion for example may require a different mode of analysis compared to a more limited spread of new technology.

2 A good example here is the One-Laptop-per-Child Programme associated with the MIT Media Lab.

3 Though problems will occur once new technologies need to be absorbed in the rural part of the economy.
} 
these are tendencies rather than iron-laws. Validity may depend among other things on the type of IT with which we happen to be concentrated.

Quite a lot of empirical research has already gone into testing these expectations. Table 2 for example shows a broad correlation between income per country grouping and adoption of IT.

More precise techniques (such as multiple regression analysis) have statistically confirmed the role of income and other predicted variables such as education and infrastructure (Dewan et al. 2004). Such cross-country research has sought in other words to explain the observed global digital divide. Within-country divides have also been confirmed though to a lesser extent (Donner 2008). These divides are also explained by technological dualism in that those in urban areas live in conditions that are closer to those in developed countries, from the point of view of income, skills, infrastructure, literacy and so on.

\section{Exceptions: Yet Another Curve}

Recall that according to World Bank research developed country innovations rarely spread beyond $25 \%$ of the population in developing countries, a fact which I ascribed to technological dualism across and within countries. Some forms of IT however constitute a striking exception to this general pattern, especially the spread of mobile phones in developing regions. Consider the entries in Table 3 which show mobile penetration and per capita income for a selected sample of rich and poor countries.

The data portray a unique situation in the history of (dependent) technological relationships between rich and poor countries, namely, that some of the latter achieved (in 2010) penetration rates that are substantially higher than the former. This is the case for example with Surinam and Vietnam as against Japan and the USA. Other developing countries have reached the same rate as the two rich countries. What makes this performance all the more remarkable is that the diffusion of mobiles began later in the poor as against the rich countries.

What are the implications of these patterns for the Rogers curve? Two possibilities suggest themselves. In Fig. 3a I have drawn a curve for the developing countries which in the early years lies below that of the original curve for developed countries (because of an initially later beginning of the process for the former). By 2010 however the rate of penetration exceeded that of the developed countries. The second possibility is where the penetration rates were roughly equal at the end of the period (though again in the early stages of the period the poor countries lag behind the rich).

Table 2 Diffusion of IT per country grouping (2004)

\begin{tabular}{lll}
\hline Country grouping according to the World Bank & $\begin{array}{l}\text { Internet users } \\
\text { (per 1000 people) }\end{array}$ & $\begin{array}{l}\text { Mobile subscribers } \\
\text { (per 1,000 people) }\end{array}$ \\
\hline High-income (e.g. UK, USA, Japan) & 480 & 767 \\
Upper-middle income (e.g. Mexico) & 133 & 490 \\
Low-middle income (e.g. Honduras, Namibia) & 70 & 255 \\
Low-income (e.g. Ethiopia, Pakistan) & 20 & 48 \\
\hline
\end{tabular}

Figures are averages of the four country groupings

Source: World Bank (2006) 
Table 3 Rates of penetration and per capita income, selected countries, 2010

Source: ICT-eye, CIA World Factbook

\begin{tabular}{lcc}
\hline & $\begin{array}{l}\text { Rates of } \\
\text { penetration }\end{array}$ & $\begin{array}{l}\text { Per capita income } \\
\text { (dollars) }\end{array}$ \\
\hline Selected developing countries & & \\
Mauritius & 91.67 & 14,000 \\
Mongolia & 91.09 & 3,600 \\
Nepal & 109.6 & 1,200 \\
Mauritania & 79.34 & 34,000 \\
Moldova & 88.59 & 2,500 \\
Surinam & 169.64 & 9,700 \\
Vietnam & 175.30 & 3,100 \\
Selected developed countries & & \\
Japan & 95.39 & 34,000 \\
USA & 89.86 & 47,200 \\
\hline
\end{tabular}

I turn next to an explanation of these figures, an explanation which has to do with technological leapfrogging in mobile phones and other types of IT.

\section{Leapfrogging}

The notion of leapfrogging refers to the possibility of a developing country bypassing the stages in the process through which countries were previously expected to pass. Leapfrogging generally allows diffusion to proceed more rapidly than it otherwise would. It is thus a potential explanation of the diagrams in Fig. 3.

Mobile phones are most readily associated with this concept but the transition from analog to digital switching technology in the 1980's also falls under the heading of leapfrogging. Digital switching allows of leapfrogging for two main reasons. One is that 'integrating the new electronic switching exchanges into an electromechanical infrastructure is much more expensive and technically complex than building a network of entirely electronic switching technology from scratch'(Antonelli 1990). The second reason is that it is developed rather than developing countries that tend to suffer from the burden of large, well-established electromechanical networks. Taken together these factors imply that developing countries 'had a remarkable opportunity to completely leapfrog the electromechanical technology, avoiding the expense of replacing obsolete (though young in age) capital stock and problems of technological cumulativity, and start their telecommunications infrastructure from scratch' (Antonelli 1990).

Not all developing countries, however, were well-placed to take advantage of the opportunity thus afforded. While some of them were indeed able to leapfrog the previous technology by adopting the new switching technology more rapidly than the developed countries, others were not. The most rapid rates of diffusion occurred among the first and second-tier newly industrializing countries from Asia (see Table 4).

The table displays the change in the ratio of electronic lines to total switching capacity for selected NICS on the one hand and a few developed countries on the other. The most impressive case is that of Korea whose ratio went from 0\% in 1977 to over $70 \%$ in 1987 (higher than two of the developed countries). This performance (and that of other countries in the region) was due partly to high rates of growth, investment and skills and partly also 
Fig. 3 New s-shaped curves
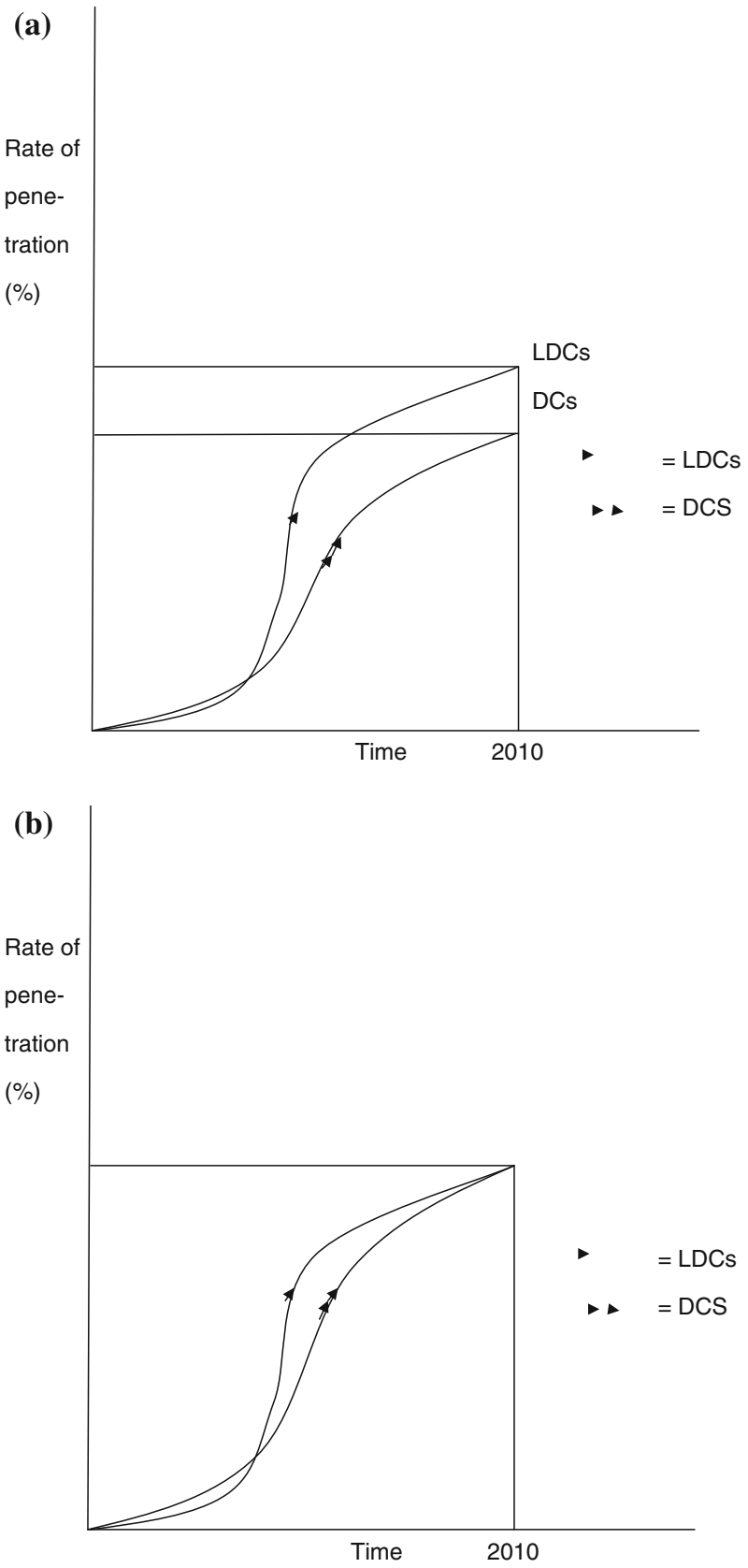

to the strategic importance that was assigned to investments in telecommunications by the governments concerned (Hanna et al. 1996). Lacking these characteristics, many other (poorer) developing countries were largely bypassed by the opportunity for leapfrogging in digital switching. Indeed many such countries continue to use analog switching technology. 
Table 4 Leapfrogging in telecommunications

Source: Antonelli (1990)

Table 5 Leapfrogging in mobile phones

Source: World Bank, ICT-at a glance tables
Share of electronic switching capacity to total exchange lines (\%)

\begin{tabular}{lrr}
\cline { 3 - 3 } & 1977 & 1987 \\
\hline Selected NICS from Asia & 0.0 & 50.7 \\
Thailand & 0.0 & 70.3 \\
Rep. Korea & 4.0 & 64.5 \\
Singapore & 7.4 & 64.3 \\
Malaysia & 14.3 & 63.5 \\
Hong Kong & \\
Selected developed countries & 10.2 & 76.2 \\
USA & 14.1 & 55.8 \\
Canada & 7.0 & 48.4 \\
UK & & \\
\hline
\end{tabular}

\begin{tabular}{lll}
\hline & \multicolumn{2}{l}{ Share of mobile to total phones } \\
\cline { 3 - 3 } & 2000 & 2005 \\
\hline Selected African countries & & \\
Kenya & 0.28 & 0.94 \\
Mali & 0.25 & 0.91 \\
Ghana & 0.39 & 0.89 \\
Selected developed countries & & \\
Canada & 0.2 & 0.47 \\
France & 0.46 & 0.57 \\
USA & 0.36 & 0.53 \\
\hline
\end{tabular}

Mobile phones, by contrast, offer a much more widespread opportunity for leapfrogging in developing countries (see Table 5).

The table shows that over the period 2000-2005 three Sub-Saharan Africa countries had achieved a much higher ratio of mobiles to total telephones. In part the difference between Tables 4 and 5 reflects cost differences between the two technologies. For example, relative to digital switching mobile phones do not require such a costly infrastructure and skills are much less of a constraint to effective use. Much of the rapid and extensive growth of the latter technology, moreover, 'reflects the process by which it has been financed. Unlike most fixed-wire telephone systems railroads and electrical grids, mobile phone technology has been introduced into most developing countries by well-funded private entrepreneurs working within a relatively competitive environment. As a result, the creation of necessary infrastructure for these systems has not been held back by the government financing and other constraints that slowed the diffusion of other technologies' (World Bank 2008, p. 75).

The final issue I will discuss concerns the uniqueness of the mobile experience. If it can be copied by other technologies there is clearly more reason to be optimistic about the future than when this experience is thought to be more nearly a one-off. The balance of opinion on the topic, as I read it, tends towards the latter view, that is, that mobiles are a 
distinctly rare opportunity for leapfrogging. 'Its very nature', according to one observer 'makes it an especially good leapfrogger: it works using radio, so there is no need to rely on physical infrastructure such as roads and phone wires; base-stations can be powered using their own generators in places where there is no electrical grid, and you do not have to be literate to use a phone, which is handy if your country's education system is in a mess' (The Economist 2008).

\section{Conclusions}

In developed countries one well-known model of the diffusion of technology is the Rogers S-shaped curve. This curve generally works quite well in the context of rich countries where the vast majority of new technologies are developed. The main task of the paper has been to consider the shape of this curve in the developing countries. The first part considers what occurred in the historical perspective of technologies imported from the rich countries. The result here is that most such technologies do not spread at all in the manner described by Rogers. Most tellingly, they do not typically spread beyond 25 per cent of the population. The difference between rich and poor countries in this respect was attributed to the concentration of innovations in and for the former as opposed to the latter i.e. to technological dualism. At the other extreme however are certain relatively recent IT technologies that perform better in some of the poorest countries than certain developed countries. I am referring here mainly but not only to mobile phones. Here again the original S-shaped curve has to be modified to reflect this exceptional performance, which was attributed mainly to the favorable leapfrogging characteristics of mobile phones.

Open Access This article is distributed under the terms of the Creative Commons Attribution Noncommercial License which permits any noncommercial use, distribution, and reproduction in any medium, provided the original author(s) and source are credited.

\section{References}

Antonelli, C. (1990). The diffusion of advanced telecommunications in developing countries. Paris: OECD. Dewan, S., Ganley, D., \& Kraemer, K. (2004). Across the digital divide: a cross-country analysis of the determinants of IT. Working paper, Graduate School of Management, University of California, Irvine.

Donner, J. (2008). Research approaches to mobile use in the developing world: a review of the literature. The Information Society, 24(3), 140-159.

Hanna, N., Boyson, S., \& Gunaratne, S. (1996). The East Asian miracle and information technology. World Bank discussion papers, nr. 326.

National Science Foundation. (2010). Science and engineering indicators. Arlington, USA.

Rogers, E. (Ed.) (1983). The diffusion of innovations. New York, The Free Press.

Singer, H. (1970). Dualism revisited: A new approach to the problems of the dual society in developing countries. Journal of Development Studies, 7, 60-75.

Stewart, F. (1977). Technology and underdevelopment. London: Macmillan.

The Economist. (2008). Of internet cafes and power cuts (print edn). London.

World Bank. (2006). Information and communications for development. Washington, DC.

World Bank. (2008). Global economic prospects. Washington. DC. 